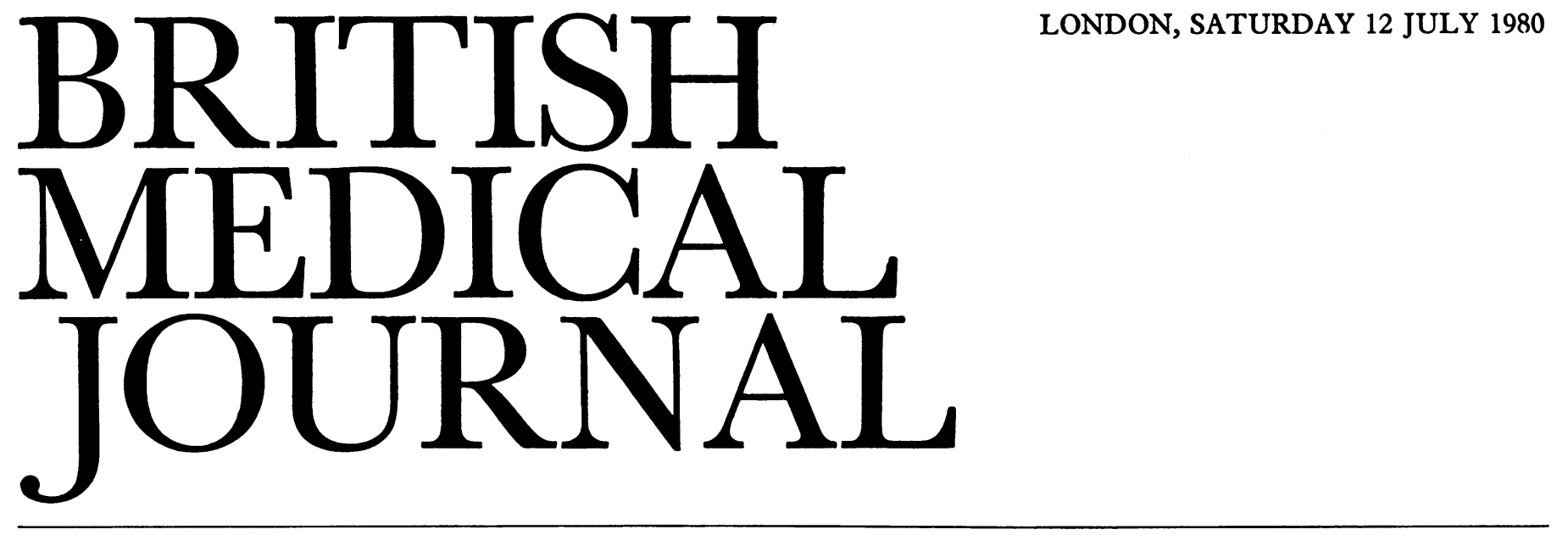

\title{
Drug interaction with oral contraceptive steroids
}

So much has been written about drug interactions that the sheer volume of print makes it difficult for most doctors to appreciate which interactions are clinically important. Drug interactions with oral contraceptives is a relative newcomer. In the '50s and ' 60 s the doses of the contraceptive steroids used were much larger than were really needed, but with the introduction of lower dose preparations problems have begun to appear. There is little convincing clinical evidence that contraceptive steroids can interfere with the response to other drugs $^{12}$; the cause for concern is that other drugs may cause failure of contraception in women taking the contraceptive pill. How common is this problem and which drugs have been implicated?

The first report of contraceptive failure in women taking other drugs with their oral contraceptives appeared in 1971. Reimers and Jezek ${ }^{3}$ found an increased incidence of breakthrough bleeding in women taking oral contraceptives who were also taking rifampicin for the treatment of tuberculosis. Since then at least 17 pregnancies have been recorded in users of contraceptive steroids given rifampicin. ${ }^{4}$ Rifampicin is a potent inducer of hepatic microsomal enzymes in man and reduces the effectiveness of other drugs such as warfarin ${ }^{5}$ and tolbutamide. ${ }^{6}$ In relation to oral contraceptives Bolt et $a l^{7} 8$ showed that rifampicin accelerated the elimination of radioactive ethinyloestradiol from plasma and that this accelerated elimination was due to a more rapid rate of hydroxylation of ethinyloestradiol by the drug metabolising enzymes in the liver. Rifampicin also diminishes the plasma concentrations of the progestogen $^{9}$ as well as the oestrogen component of the contraceptive preparation. The changes seen in these studies were substantial, but they varied from patient to patient; in practical terms, the conclusion must be that oral contraceptives should not be given to women being treated with rifampicin, and that alternative methods should be used.

Breakthrough bleeding and failure of oral contraception have also been noted in patients taking anticonvulsants. ${ }^{10} \mathrm{At}$ least 25 pregnancies have been reported, ${ }^{11}$ and the Committee on Safety of Medicines has received a further 23 reports. Phenytoin has been implicated most often, but phenobarbitone, phenytoin, primidone, and carbamazepine are all welldocumented inducers of microsomal enzymes in man, ${ }^{12}$ and hence might be expected to increase the rates of metabolism of the contraceptive steroids. In addition, these anticonvulsant drugs increase the binding of the progestogens to sex-hormone binding globulin, thereby lowering the free concentration of the steroids. ${ }^{13}$ Though few clinical studies have been completed, experience with young women with epilepsy suggests that in most cases good cycle control can be achieved by using a contraceptive preparation containing $50 \mu \mathrm{g}$ ethinyloestradiol. If breakthrough bleeding still occurs then the woman should be given in addition a preparation containing $30 \mu \mathrm{g}$ ethinyloestradiol, so raising her daily dosage to $80 \mu \mathrm{g}$ to compensate for her more rapid metabolism of the drug. If anticonvulsant treatment is stopped then the daily dose of ethinyloestradiol should be reduced to $30 \mu \mathrm{g}$.

Antibiotics may also cause contraceptive failure in women taking the contraceptive pill. Constructive advice is difficult to give, since the frequency of adverse drug interactions is extremely difficult to calculate. Based on the same published data, directly contradictory advice about appropriate courses of action has been offered.14 15 The Committee on Safety of Medicines has received 38 reports of pregnancies occurring in women who have been given antibiotics (other than rifampicin) at the same time as their oral contraceptives. Dossetor ${ }^{15}$ described three pregnancies in women receiving ampicillin with contraceptive preparations, and a further report describing a pregnancy in a woman given tetracycline with her oral contraceptive appeared in the $B M \mathcal{F}$ earlier this year. ${ }^{16}$

Ethinyloestradiol is well absorbed in man, but on average $60 \%$ of the drug is metabolised ${ }^{17}$ on its first pass into the body to form sulphate and glucuronide conjugates. ${ }^{18}$ These conjugates are excreted in the bile and then may be hydrolysed by the bacteria in the gut to produce the unchanged drug, which is reabsorbed. Nevertheless, while ethinyloestradiol undergoes this enterohepatic recirculation in $\operatorname{man}^{17}$ the progestogensnorethisterone and levonorgestrel-probably do so only as inactive metabolites. Furthermore, though the bacteria in the gut possess enzymes that hydrolyse glucuronide conjugates, ${ }^{19}$ there is no clear evidence that they can also deal with sulphate conjugates. These processes are upset by broad-spectrum antibiotics, which kill the bacteria that hydrolyse the conjugates, thereby preventing the enterohepatic recirculation of ethinyloestradiol and so producing a fall in its plasma concentration. For example, ampicillin reduces the plasma and urinary concentrations of oestriol. ${ }^{20} \mathrm{~A}$ recent study in America, ${ }^{21}$ however, examined the effect of ampicillin in 11 women taking contraceptives and found no effect on follicle-stimulating hormone, oestradiol, or progesterone. Ampicillin was given for 16 days, rather longer than is usual, and the first blood samples were not taken until day 13 , so that possibly an interaction could have been missed since the gut bacteria rapidly develop resistance to ampicillin. ${ }^{22}$ Furthermore, only certain women 
appreciable variations in the excretion of steroid conjugates in the bile. ${ }^{23}$ Possibly, too, women may be more at risk if the antibiotic is given at a sensitive stage in the cycle.

The counsel of perfection is to advise the use of alternative contraceptive precautions in all women receiving broadspectrum antibiotics and all oral contraceptive preparations. Even so, further evidence about the size of the risk is needed before any such definite advice is given. Especially valuable would be guidelines that might help identify groups of women with unusual susceptibility to interactions of this kind.

1 Prange AJ. Estrogen may well affect the response to antidepressants. fAMA 1972;219:143-4.

2 Teresa E de, Vera A, Ortigosa J, Pulpon LA, Arus AP, Artaza M de. Interaction between anticoagulants and contraceptives: an unsuspected finding. $\mathrm{Br}$ Med $\mathcal{F} 1979 ; \mathrm{i}: 1260-1$.

${ }^{3}$ Reimers D, Jezek A. Rifampicin und andere Antituberkulostatika bei gleichzeitiger oraler kontrazeption. Praxis Pneumol 1971 ;25:255-62.

${ }^{4}$ Breckenridge AM, Back DJ, Orme M. Interactions between oral contraceptives and other drugs. Pharmacology and Therapeutics 1979;7:617-26.

5 O'Reilly RA. Interaction of sodium warfarin and rifampicin. Studies in man. Ann Intern Med 1974;81:337-40.

6 Syvalahti EKG, Pihlajamaki KK, Iisalo EJ. Rifampicin and drug metabolism. Lancet 1974 ;ii:232-3.

${ }^{7}$ Bolt HM, Bolt M, Kappus H. Interaction of rifampicin treatment with pharmacokinetics and metabolism of ethinyloestradiol in man. Acta Endocrinol $(K b h)$ 1977;85:189-97.

8 Bolt HM, Kappus H, Bolt M. Effect of rifampicin treatment on the metabolism of oestradiol and $17 \alpha$-ethinyloestradiol by human liver microsomes. Eur f Clin Pharmacol 1975;8:301-7.

- Back DJ, Breckenridge AM, Crawford FE, et al. The effect of rifampicin on norethisterone pharmácokinetics. Eur $\mathcal{f}$ Clin Pharmacol 1979;15: 193-7.

10 Janz D, Schmidt D. Antiepileptic drugs and failure of oral contraceptives. Lancet 1971 ; $: 1113$.

11 Coulam CB, Annegers JF. Do anticonvulsants reduce the efficacy of oral contraceptives? Epilepsia $1979 ; 20: 519-26$.

12 Breckenridge AM. Clinical implications of enzyme induction. In: Parke DV, ed. Enzyme induction. New York: Raven Press, $1975: 273-301$.

${ }^{13}$ Backstrom T, Sodergard $R$. The influence of antiepileptic drugs on steroid plasma levels and binding during the menstrual cycle. Acta Endocrinol (Kbh) $1977 ; 85$, suppl 212:42.

14 Stockley IH. Drug interactions. An appraisal of the current situation. Trends in Pharmacological Science 1979;1:VI.

15 Dossetor J. Drug interactions with oral contraceptives. $\mathrm{Br} \mathrm{Med} \mathcal{F} 1975$;iv: 467-8.

${ }^{16}$ Bacon JF, Shenfield GM. Pregnancy attributable to interaction between tetracycline and oral contraceptives. $\mathrm{Br} \mathrm{Med} \mathcal{F} 1980 ; 280: 293$.

17 Back DJ, Breckenridge AM, Crawford FE, et al. An investigation of the pharmacokinetics of ethynylestradiol in women using radioimmunoassay. Contraception $1979 ; 20: 263-73$.

${ }^{18}$ Cargill DI, Steinetz BG, Gosnell E, et al. Fate of ingested radiolabeled ethynylestradiol and its 3-cyclo pentyl ether in patients with bile fistulas. F Clin Endocrinol Metab 1969;29:1051-61.

19 Hawksworth G, Drasar BS, Hill MJ. Intestinal bacteria and the hydrolysis of glycosidic bonds. 7 Med Microbiol 1971;4:451-9.

20 Willman K, Pulkkinen MO. Reduced maternal plasma and urinary estriol during ampicillin treatment. Am $\mathcal{f}$ Obstet Gynecol 1971;109:893-6.

21 Friedman CI, Huneke AL, Kim MH, Powell J. The effect of ampicillin on oral contraceptive effectiveness. Obstet Gynecol 1980;55:33-7.

${ }^{22}$ Leigh DA, Reeves DS, Simmons K, Thomas AL, Wilkinson PJ. Talampicillin: a new derivative of ampicillin. $B r$ Med $\mathcal{F} 1976$;i:1378-80.

${ }^{23}$ Helton ED, Goldzieher JW. Metabolism of ethynylestrogens. $\mathcal{F}$ Toxicol Environ Health 1977;3:231-41.

\section{Staging lung cancer}

Stage and histological type are the crucial factors in management of patients with lung cancer. The main subgroup for which a separate treatment policy is vital is the category of small-cell (oat-cell) carcinoma. The encouraging results of chemotherapy for this type of lung cancer ${ }^{1}$ contrast with the relentless resistance of the other histological varieties to any treatment other than surgery. Cancers of these other cell types need, therefore, to be divided into surgically resectable and inoperable, and there is growing interest in new techniques for this purpose.

A study carried out on over 100 patients with lung cancer has presented a model for sequential staging. ${ }^{2}$ Physical examination, chest radiography, and laboratory tests should be followed by a series of isotope and computed tomography scans. Histological verification of the extent of disease delineated by the scanning techniques then provides the final staging. The lessons to be learned from this logical approach are, firstly, that the simplest of investigations will identify some patients with metastatic disease. Secondly, computed tomography in conjunction with whole-body gallium scans showed metastases in the bones, liver, or brain of a further 29 of 94 patients. Metastases in the kidney or adrenal glands were camouflaged by the excretion of gallium into the gut in a few cases. In this study computed tomography scanning was confined to the brain, but in a British study ${ }^{3}$ computed tomography of the whole body found evidence of metastatic disease in $60 \%$ of patients; deposits were picked up in the pleura, the mediastinum, the hilar and paratracheal glands, and the liver. Computed tomography and gallium scanning are also useful for identifying and measuring the extent of the primary tumour in the bronchus. Conventional isotope scans of liver, brain, and bone rarely add new information and might be dispensed with in favour of tomography and gallium tests, with the proviso that the latter have a known but low falsepositive rate.

Surgical staging, by biopsy of lymph nodes, marrow, and the liver, adds very little to clinical staging by these techniques, though aspiration of bone marrow is useful in patients with small-cell cancer, in whom infiltration (which is quite common) can be estimated at the same time as the marrow reserve-information relevant to subsequent treatment with cytotoxic drugs.

Once staging procedures have been completed the clinician has a choice of systems of nomenclature. The UICC or TNM classification ${ }^{4}$ recommends for all tumour types a description of the stage of the primary tumour, the lymph nodes, and metastatic lesions. These classifications are tedious and have a tendency to mushroom as each edition of the TNM book appears. The latest version adds a fourth stage to the pre-existing three for no very obvious reason. Specifying the three basic stages of lung cancer is of proved value in planning treatment for tumours of cell types other than small-cell and for comparison of studies from different centres; and to some degree (related to the relevant treatment options) it gives an idea of prognosis. Thus stage $I$, which is a small primary tumour, usually surgically resectable, carries a five-year survival rate of $40 \%$. In stage II, a slightly larger primary tumour with spread to the draining lymph nodes, survival drops to $12 \%$. The figure falls below $1 \%$ when visceral metastases develop (stage III). The subgroup of patients who present with a Pancoast tumour in the apex of the lung are an exception: in many series treated by radiotherapy five-year survival has been around $20 \%$.

A different system is used for the small-cell variety of lung cancer. Two categories of disease have been defined, one "limited" to the hemithorax and the other "extensive" with spread to other areas. Chemotherapy and radiotherapy are extremely successful, at least in the short term, in the "limited" variety; and indeed with more aggressive chemotherapy survival for over two years has been achieved, which compares favourably with an average survival of three months in may be at risk from interactions of this kind, since there are 